ITC 3/48

Journal of Information Technology and Control

Vol. 48/No. 3/2019

pp. 373-388

DOI 10.5755/j01.itc.48.3.20627

\section{A Physics-Based Novel Approach for Travelling Tournament Problem: Optics Inspired Optimization}

Received 2018/04/22

Accepted after revision 2019/07/16

\title{
A Physics-Based Novel Approach for Travelling Tournament Problem: Optics Inspired Optimization
}

\author{
B. Alatas, H. Bingol \\ Department of Software Engineering; Firat University; Elazig, Turkey \\ phone:+9042423700000; e-mails: balatas@firat.edu.tr, harun_bingol@hotmail.com
}

Corresponding author: balatas@firat.edu.tr

Computational intelligence search and optimization algorithms have been efficiently adopted and used for many types of complex problems. Optics Inspired Optimization (OIO) is one of the most recent physics inspired computational intelligence methods which treats the search space of the problem to be optimized as a wavy mirror in which each peak is assumed to reflect as a convex mirror and each valley to reflect as a concave one. Each candidate solution is treated as an artificial light point that its glittered ray is reflected back by the search space of the problem and the artificial image is formed based on mirror equations adopted from Optics, as a new candidate solution. In this study, OIO for the first time has been designed as a solution search strategy for travelling tournament problem which is one of the current sport problems and aids to minimize transportation and total movement of teams. Furthermore, this problem has been firstly solved by League Championship Algorithm and obtained results from both synthetic and real datasets have been compared. By this study, new application areas for OIO and LCA have been introduced. Obtained results show the superiority of OIO which is a novel algorithm and seems to efficiently solve many complex problems.

KEYWORDS: Computational intelligence optimization, optics inspired optimization, travelling tournament problem, artificial intelligence.

\section{Introduction}

Most of the search and optimization methods require mathematical models of the system. Establishing a mathematical model for complex systems is often difficult. Even if the model is established, the solution time cannot be used due to the huge cost. Classical search and optimization algorithms are insufficient for complex large scale combinatorial and nonlinear search and optimization problems. 
Such algorithms are not effective in adapting them to interested problems. This, in many cases, requires some assumptions that may be difficult to validate. Often due to the natural solution mechanisms of classical search methods, the problem concerned is modeled such that the method will manage it. The solution strategy of classical optimization methods is usually dependent on the type of objectives and constraints and on the type of variables. Their effectiveness is also highly dependent on the solution space in the problem model, the number of constraints, and number of decision variables. Another important shortcoming is that they cannot present general solution purpose strategies that can be utilized in the case of different types of variables, objectives, and constraints. In other words, classical methods solve models that have a specific type of objective function or constraint functions. However, many optimization problems in management, sports, engineering, economy, computer, etc., require different types of variables, objective functions, and constraints in formulations simultaneously. Therefore, computational intelligence optimization methods are purposed and efficiently adapted. These methods have become very popular in recent years because they are computationally powerful and their transformations are easy [1].

General-purpose computational intelligence search algorithms are divided into various groups such as biology-based, social-based, chemical-based, physics-based, music-based, mathematics-based, sportsbased, swarm-based, plant-based, and water-based. Their combinations can also be considered as hybrid category. Genetic algorithm, ant colony algorithms, and differential evolution algorithm are biologically based; simulated annealing algorithm and charged system search algorithm are physics based; human mental search is social based; artificial chemical reaction optimization algorithm is chemistry-based and musical composition method is music-based algorithm and models [3].

Optics Inspired Optimization (OIO) is one of the most recent population-based physics inspired algorithms proposed by Kashan [23, 24]. OIO is inspired by the optical characteristics of concave and convex mirrors that can be utilized to solve different types of complex large scaled problems. When the light rays strike on the concave mirror, they reflect towards the principal axis and converge. When the light rays fall on the convex mirror, they reflect away from the principal axis and diverge. Exploration and exploitation capabilities of OIO are controlled by these concave and convex mirror phenomena.

In this study, OIO has been used as a solution search strategy for the first time in the Travelling Tournament Problem (TTP), which aims to minimize the moving problems of the current sports problems and the total movement of the sports teams. The obtained results are compared with the League Championship Algorithm (LCA) which is one of the most recent sports inspired artificial intelligence optimization algorithms [25].

The organization of this work is as follows. In Section 2, information about computational intelligence optimization algorithms and their advantages are discussed. Physics-based OIO is briefly introduced in Section 3. In Section 4, TTP is explained in detail with examples. In Section 5, designing of OIO for the TTP that confronts the league is explained. The performance of the OIO optimized TTP is experimentally investigated in the real and synthetic dataset and the performance comparisons with the sports-based LCA are presented for the first time. Section 6 contains comments on what kind of problems OIO can be efficiently used for and what can be done in future works.

\section{Computational Intelligence Search and Optimization}

In most real-life problems, the solution space of the problem is infinite or so large that all solutions cannot be evaluated. For this to be acceptable, it is necessary to create and evaluate the candidate solutions and find a good solution within an acceptable time. The evaluation of solutions in such a way that they are acceptable for such problems actually means the evaluation of "some solutions" in the entire solution space. The way in which some solutions are chosen and how they are selected varies according to the computational intelligence technique $[2,3,5]$.

Computational intelligence algorithms provide general solution strategies when the optimization problem may have a structure in which the exact solution finding process cannot be identified. When a mathematical model cannot be constructed or when constructed model has different types of variables, objective functions, and constraint functions, they can also 
be efficiently utilized. Their computing power is good and their transformations are easy. They are adaptable for different types of complex problems.

For clarity, computational intelligence algorithms can be much simpler in terms of decision makers. They can be used as part of learning and precise solution finding. Definitions made by mathematical formulas often ignore the most difficult parts of real-world search and optimization problems (what objectives and what constraints should be used, which alternatives should be tested, how to gather problem data). In the case that the data used in determining the model parameters have noise, worse solutions may be obtained than the suboptimal solution that the computational intelligence search techniques can produce. Due to many advantages, computational intelligence algorithms are densely and efficiently being used as search strategy in many search and optimization problems.

General-purpose computational metaheuristic search and optimization algorithms can be divided to ten categories according to different inspiration fields: as sociology, music, physics, biology, swarm, sports, chemistry, water, plant, and mathematics. Categorization is depicted in Table 1.

Table 1

Computational intelligence search and optimization methods

\begin{tabular}{l|l}
\hline \multicolumn{2}{c}{ Computational Intelligence Algorithms } \\
Physics-based & $\begin{array}{l}\text { Optics inspired optimization, Ions } \\
\text { motion optimization }\end{array}$ \\
\hline Music-based & $\begin{array}{l}\text { Harmony search, Musical composition } \\
\text { algorithm }\end{array}$ \\
\hline Swarm-based & $\begin{array}{l}\text { Particle swarm optimization, Ant } \\
\text { colony algorithm }\end{array}$ \\
\hline Biology-based & $\begin{array}{l}\text { Genetic algorithm, Clonal selection } \\
\text { algorithm }\end{array}$ \\
\hline Math-based & $\begin{array}{l}\text { Base optimization algorithm, Golden } \\
\text { sine algorithm }\end{array}$ \\
\hline Plant-based & Plant growth optimization \\
\hline Social based & $\begin{array}{l}\text { Parliamentary optimization algorithm, } \\
\text { Social based algorithm }\end{array}$ \\
\hline Water-based & Water drops algorithm \\
\hline Sports based & League championship algorithm \\
\hline $\begin{array}{l}\text { Chemistry } \\
\text { based }\end{array}$ & $\begin{array}{l}\text { Artificial chemical reaction } \\
\text { optimization algorithm }\end{array}$ \\
\hline
\end{tabular}

Physics-based computational intelligence optimization methods mimic physical rules [9]. The most popular physics-based methods are magnetic optimization algorithm [46], ions motion optimization [22], central force optimization algorithm [47], and OIO [23, 24]. Social based optimization algorithms are inspired by behaviors of people, human learning mechanism, and many features associated with the social situation of the people [36, 28]. Some of the popular social based optimization algorithms are named as Parliamentary optimization algorithm [8], teaching-learning based optimization [39], and social based algorithm [38].

Harmony search [19] and musical composition algorithm [33] are music based methods. Artificial chemical reaction optimization algorithm [4] is a chemistry- based method. Genetic algorithm [21] and clonal selection algorithm [14] are well-known biological based algorithms. Base optimization algorithm [42] and golden sine algorithm [45] are mathematics based methods.

Particle swarm optimization [26], chicken swarm optimization [32], and ant colony algorithm [15] are some of the popular swarm inspired search and optimization algorithms proposed inspiring from swarm intelligence systems in nature.

Plant-based algorithms have been proposed by inspiration from plant intelligence [3]. Water-based algorithms have been proposed inspiring from the process in hydrology [35].

\section{Optics Inspired Optimization}

OIO is one of the most recent population-based physics inspired algorithms proposed by Kashan [23-25]. OIO is inspired by the optical characteristics of concave and convex mirrors that can be utilized to solve different types of complex search problems. When the light rays strike on the concave mirror, they reflect towards the principal axis and converge. When the light rays fall on the convex mirror, they reflect away from the principal axis and diverge. Exploration and exploitation capabilities of OIO are controlled by these concave and convex mirror phenomena. The pictorial representation of an artificial image formation (new candidate solution generation) is shown in Figure 1 
Figure 1

Demonstration of the law of reflection when light rays fall on convex mirror [23]

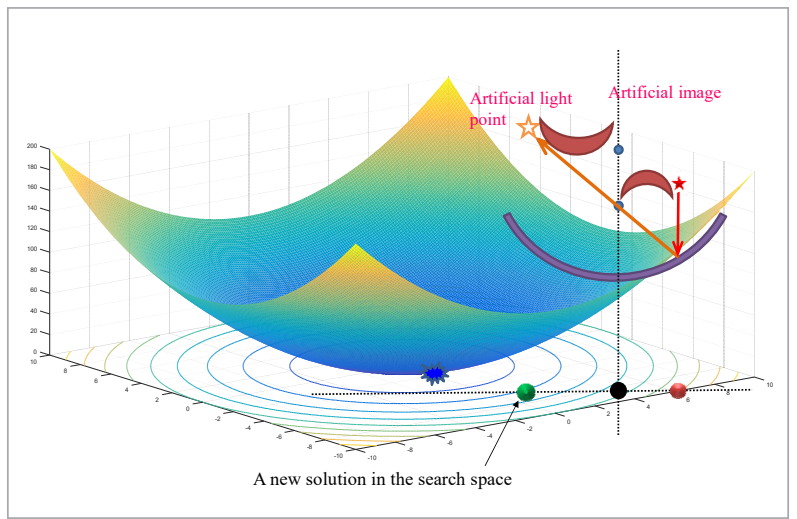

where each valley represents the concave mirror and peek represents a convex mirror [23, 29].

The candidate solutions in OIO are represented by artificial light points (ALP). Their rays strike at the mirror and reflect back to form artificial images (new candidate solutions) with the help of artificial mirror (AM). The reflected surface can be convex or concave. The variables used in OIO equations are described in Table 2.

A number of artificial light points (points in $R_{n+1}$ whose mapping in $R_{n}$ are candidate solutions for the interested problem) are assumed to be sitting in front of an artificial wavy mirror (function surface) reflecting their images. OIO treats the surface of the function to be minimized or maximized as the reflecting mirror composed of peaks and valleys. Each valley is considered as a concave reflective surface and each peak is considered as a convex reflective surface [24].

Distances and radius have been computed as in Equations (1) and (2). After computing these values, Equation (3) is applied to obtain $q_{j, i_{k}}^{t}$.

$$
p_{j, i_{k}}^{t}=s_{j, i_{k}}^{t}-f\left(\vec{F}_{i_{k}}^{t}\right)
$$

$r_{i_{k}}^{t}=m_{i_{k}}^{t}-f\left(\vec{F}_{i_{k}}^{t}\right)$

$$
\frac{2}{r_{i_{k}}^{t}}=\frac{1}{p_{j, i_{k}}^{t}}+\frac{1}{q_{j, i_{k}}^{t}} \Rightarrow q_{j, i_{k}}^{t}=\frac{r_{i_{k}}^{t} p_{j, i_{k}}^{t}}{2 p_{j, i_{k}}^{t}-r_{i_{k}}^{t}} .
$$

Given the fact that

$$
H O_{j, i_{k}}^{t}=\left\|\vec{o}_{j}^{t}-\vec{F}_{i_{k}}^{t}\right\|
$$

the image height of the ALP $j$ can be calculated as in Equation (5):

$$
H I_{j, i_{k}}^{t}=-H O_{j, i_{k}}^{t} \frac{q_{j, i_{k}}^{t}}{p_{j, i_{k}}^{t}} .
$$

\begin{tabular}{|c|c|}
\hline $\begin{array}{l}\text { Formulations and } \\
\text { Variables }\end{array}$ & Meaning \\
\hline$\vec{O}_{j=}^{t}\left[O_{j 1}^{t} O_{j 2}^{t} \ldots O_{j n}^{t}\right]_{1 x n}$ & $\begin{array}{l}\text { Position of artificial light point (ALP) } \\
j \text { in the } n \text {-dimensional search space } \\
\text { in iteration } t \text { (the } j \text { th solution in the } \\
\text { population). }\end{array}$ \\
\hline$\vec{F}_{i_{k}}^{t}=\left[f_{i k^{1}}^{t} f_{i k^{2}}^{t} \ldots f_{i k^{n}}^{t}\right]_{1 x n}$ & $\begin{array}{l}\text { Individual in the population which } \\
\text { passes the artificial principal axis } \\
\text { through itself }\end{array}$ \\
\hline$\vec{I}_{j=}^{t}\left[I_{j 1}^{t} I_{j 2}^{t} \ldots I_{j n}^{t}\right]_{1 x n}$ & $\begin{array}{l}\text { Image position of the ALP } j \text { in } \\
\text { iteration } t \text {. }\end{array}$ \\
\hline$S_{j, i_{k}}^{t}$ & $\begin{array}{l}\text { Position of the ALP } j \text { on the function/ } \\
\text { objective axis in iteration } t \text {. }\end{array}$ \\
\hline$p_{j, i_{k}}^{t}$ & $\begin{array}{l}\text { Distance between the position of ALP } \\
j \text { on the function/objective axis and } \\
\text { the position of artificial mirror (AM) }\end{array}$ \\
\hline$q_{j, i_{k}}^{t}$ & $\begin{array}{l}\text { Distance between the image position } \\
\text { of the ALP } j \text { on the function/objective } \\
\text { axis and the position of AM vertex } \\
\text { on the function/objective axis at } \\
\text { iteration } t \text {. }\end{array}$ \\
\hline$r_{j, i_{k}}^{t}$ & Radius of curvature of the AM \\
\hline$m_{i_{k}}^{t}$ & $\begin{array}{l}\text { Position of the center of curvature on } \\
\text { the function/objective axis }\end{array}$ \\
\hline$H O_{j, i_{k}}^{t}$ & $\begin{array}{l}\text { Height of the ALP } j \text { from artificial } \\
\text { principal axis in iteration } t \text {. }\end{array}$ \\
\hline$H I_{j, i_{k}}^{t}$ & $\begin{array}{l}\text { Image height of the ALP } j \text { from } \\
\text { artificial principal axis in iteration } t \text {. }\end{array}$ \\
\hline$K_{j, i_{k}}^{t}$ & $\begin{array}{l}\text { Value of lateral aberration relevant to } \\
\text { the AM which is reflecting the image } \\
\text { of the ALP } j \text { in iteration } t \text {. }\end{array}$ \\
\hline
\end{tabular}

\section{Table 2}

Meaning of variables and formulations 
Image position of the ALP $j$ in iteration $t$ can be computed as in Equation (6):

$$
\begin{aligned}
& \vec{I}_{j, i_{k}}^{t}=\vec{F}_{i_{k}}^{t}+H I_{j, i_{k}}^{t} \frac{\left(\vec{o}_{j}^{t}-\vec{F}_{i_{k}}^{t}\right)}{\left\|\vec{o}_{j}^{t}-\vec{F}_{i_{k}}^{t}\right\|}=\vec{F}_{i_{k}}^{t}-H O_{j, i_{k}}^{t} \frac{q_{j, i_{k}}^{t}}{p_{j, i_{k}}^{t}} \frac{\left(\vec{o}_{j}^{t}-\vec{F}_{i_{k}}^{t}\right)}{\left\|\vec{o}_{j}^{t}-\vec{F}_{i_{k}}^{t}\right\|} \\
& \Rightarrow \vec{I}_{j}^{t}=\vec{F}_{i_{k}}^{t}-\frac{q_{j, i_{k}}^{t}}{p_{j, i_{k}}^{t}}\left(\vec{o}_{j}^{t}-\vec{F}_{i_{k}}^{t}\right)=\vec{F}_{i_{k}}^{t}-\frac{r_{i_{k}}^{t}}{2 p_{j, i_{k}}^{t}-r_{i_{k}}^{t}}\left(\vec{o}_{j}^{t} \vec{F}_{i_{k}}^{t}\right) .
\end{aligned}
$$

A new consequent image position (candidate solution) is calculated according to Equations ( 7 ) and (8):

$\vec{I}_{j}^{t}=\sum_{k=1}^{K} w_{k}^{t} \vec{I}_{j, i_{k}}^{t}$

$\sum_{k=1}^{K} w_{k}^{t}=1,0<w_{k}^{t} \leq 1$.

Equation (9) is used to calculate the value of lateral aberration relevant to an AM which is reflecting the image of the ALP $j$ in iteration $t$ :

$\vec{K}_{j, i_{k}}^{t}=\frac{\left(r_{i_{k}}^{t}\right)^{2}}{2 \sqrt{\left(r_{i_{k}}^{t}\right)^{2}-\left(H O_{j, i_{k}}^{t}\right)^{2}}}-\frac{\left|r_{i_{k}}^{t}\right|}{2}$.

The flow-chart of OIO is demonstrated in Figure 2.

\section{Travelling Tournament Problem}

Travelling Tournament Problem (TTP) is one of the most popular scheduling problems in any sport. Where the team travels when traveling charts are created is an important issue. It is a problem that has arisen by imitating the traveling salesman problem [44, 20, 37].

There are professional leagues all over the world. They have great economic hedge because of the massive revenue generated by broadcast rights and ticket sales of popular matches. Therefore, the planning of these leagues is of great importance. Another important aspect is the creation of the time table for the tournament. During the season, which teams will match the other teams and the venues of the matches must be specified. Considering the distance between team numbers and locations, the time table of the Double Round Robin Tournament is used to reduce the total number of travel distances by teams [27, 12, 41].

The TTP is a problem of optimizing tournament schedule. Given $N$ teams with $N$ even, Double Round Robin Tournament is a game series in which every team plays every other team exactly once at home and once away. The game is designated as an ordered pair of competitors. $2 \times(N-1)$ slots or time periods are required to play Double Round Robin Tournament. The distance between tool positions is given as $N \times N$ distance matrix. Each team starts in their own home and goes on a trip to play in selected locations. At the end

Figure 2

Flow-chart of OIO

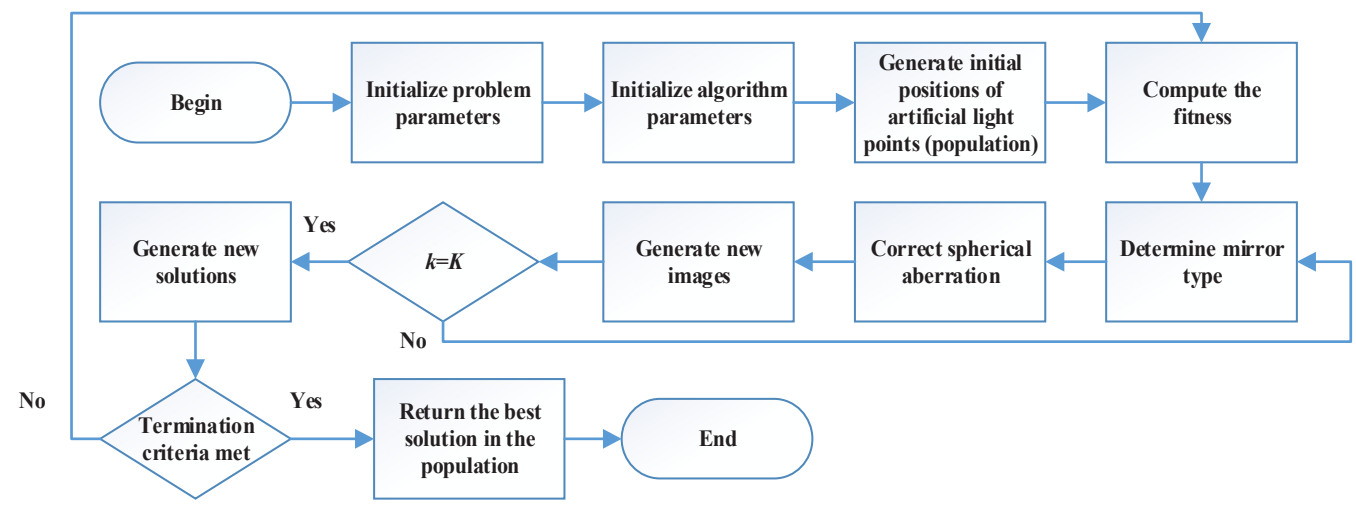


of the program, each team will return to their home if necessary. Thus, the problem is to decide on the optimal plan and to make the average travel fee less.

Input: $N$ (Number of teams), $D(N \times N$ distance matrix) Output: Teams travel in the final tournament schedule with all restrictions and least total distance

The problem can be formalized according to the following rules:

$1 N$ teams participate on the tour.

2 Every team has its own stadium.

3 Distances between stadiums are known.

The following constraints should be taken into account:

1 Each pair of teams (we can call them A and B) makes 2 matches. One of them is at A's and the other is at B's home. Thus, $2 \times(N-1)$ rounds are made and $N / 2$ matches are performed in each round $(N$ is the number of teams) (Double Round Robin restriction).

2 No team will be able to compete successive four times in their home or away on the road (Successive restriction).

3 For any pair of teams, for example, A and B, the match played at A's/B's home and the match played at B's/A's home cannot be on consecutive tours (non-repeating restriction). Thus, if the match is made at A's home this week, it cannot be done at B's home; matches should be played with other teams [44].
Table 3

The distance matrix for $6 \times 6 \mathrm{TTP}$ [11]

\begin{tabular}{|c|c|c|c|c|c|c|}
\hline & ATL & NYM & PHI & MON & FLA & PIT \\
\hline ATL & 0 & 745 & 665 & 929 & 605 & 521 \\
\hline NYM & 745 & 0 & 80 & 337 & 1090 & 315 \\
\hline PHI & 665 & 80 & 0 & 380 & 1020 & 257 \\
\hline MON & 929 & 337 & 380 & 0 & 1380 & 408 \\
\hline FLA & 605 & 1090 & 1020 & 1380 & 0 & 1010 \\
\hline PIT & 521 & 315 & 257 & 408 & 1010 & 0 \\
\hline
\end{tabular}

ATL team will play against FLA (home), NYM (home), PIT (home), PHI (away), MON (away), PIT (away), PHI (home), MON (home), NYM (away), and FLA (away) based on the program in Table 4 [35]. Looking at the distance between the cities where the teams in Table 3 are located, it will be found how much the ATL team will move through the league [11]:

$d_{A T L, P H I}+d_{P H L, M O N}+d_{M O N, P I T}+d_{P I T, A T L}+d_{A T L, N Y M}+d_{N Y M, F L A}+$ $d_{F L A, A T L}=665+380+408+521+745+1090+605=4414$

The total distance in the league will be obtained by taking the sum of the distances according to the league program for each team. This total distance gives us the value of the objective function. As this distance decreases, the solution of the problem will also be considered as successful. Therefore, TTP is exactly the problem of minimizing the total distance in the league. The NL shown in Table 5 means nation-

Table 4

Sample league program for TTP (The @ sign represents a team playing away) [11]

\begin{tabular}{|c|c|c|c|c|c|c|}
\hline Slot & ATL & NYM & PHI & MON & FLA & $\mathrm{PIT}$ \\
\hline 0 & FLA & $@ P I T$ & $@ M O N$ & $\mathrm{PHI}$ & @ATL & NYM \\
\hline 1 & NYM & @ATL & FLA & $@ \mathrm{PIT}$ & $@ \mathrm{PHI}$ & MON \\
\hline 2 & PIT & @FLA & MON & @PHI & NYM & @ATL \\
\hline 3 & @ PHI & $\mathrm{MON}$ & ATL & $@ N Y M$ & $\mathrm{PIT}$ & $@$ @LLA \\
\hline 4 & @MON & FLA & $@ P I T$ & ATL & @NYM & PHI \\
\hline 5 & $@ \mathrm{PIT}$ & @PHI & NYM & FLA & $@ M O N$ & ATL \\
\hline 6 & $\mathrm{PHI}$ & $@ M O N$ & @ATL & NYM & $@ P I T$ & FLA \\
\hline 7 & MON & $\mathrm{PIT}$ & @FLA & @ATL & $\mathrm{PHI}$ & $@ N Y M$ \\
\hline 8 & @NYM & ATL & $\mathrm{PIT}$ & @FLA & MON & $@$ PHI \\
\hline 9 & @FLA & PHI & @NYM & PIT & ATL & $@ M O N$ \\
\hline
\end{tabular}


Table 5

Solution comparison of TTP with the existing algorithms (The best values are expressed in boldface) [11]

\begin{tabular}{|c|c|c|c|c|c|c|c|c|}
\hline Work & Method & NL4 & NL6 & NL8 & NL10 & NL12 & NL14 & NL16 \\
\hline $\begin{array}{l}{[16,40} \\
34,16]\end{array}$ & Linear Programming & 8276 & 23916 & 41113 & & & & 312623 \\
\hline$[7]$ & $\begin{array}{l}\text { A combination of constraint programming and } \\
\text { lanrange relaxation }\end{array}$ & 8276 & 23916 & 42517 & 68691 & 143655 & 301113 & 437273 \\
\hline$[10]$ & Tabu Search & 8276 & 23916 & 40416 & 66037 & 125803 & 205894 & 308413 \\
\hline [30] & Unknown (data from TTP Website) & 8276 & 24073 & 39947 & 61608 & 119012 & 207075 & 293175 \\
\hline$[43]$ & “Greedy big step” Meta-Heuristic & & & 39776 & 61679 & 117888 & 206274 & 281660 \\
\hline$[31]$ & Simulated Annealing and Hill-Climbing & 8276 & 23916 & 39721 & 59821 & 115089 & 196363 & 274673 \\
\hline$[30]$ & Unknown (data from TTP Website) & & & & 59436 & 112298 & 190056 & 272902 \\
\hline [13] & $\begin{array}{l}\text { Ant Colony Optimization with Local } \\
\text { Improvement }\end{array}$ & 8276 & 23916 & 40797 & 67640 & 128909 & 238507 & 346530 \\
\hline [6] & Simulated Annealing & 8276 & 23916 & 39721 & 59583 & 111248 & 188728 & 263792 \\
\hline [18] & $\begin{array}{l}\text { Composite-Neighborhood Tabu Search } \\
\text { Approach }\end{array}$ & & & & 59583 & 111483 & 190174 & 270063 \\
\hline$[11]$ & Ant Algorithm Hyper-Heuristic & 8276 & 23916 & 40361 & 65168 & 123752 & 225169 & 321037 \\
\hline
\end{tabular}

al league and the $N$ parameter indicates the number of teams. NL8 shows that the league consists of 8 teams. Several algorithms have been searched for TTP and the test results obtained are shown in Table 5.

\section{Solution of the Travelling Tournament Problem with Optics Inspired Optimization}

Assume that the number of teams is 8. By following the constraints defined in TTP, based on the distance matrix of the cities indicated in Table 6 , the problem of minimizing the total movement of the teams through the league is achieved by OIO. League schedule for the first match is shown in Table 7 . Table 9 shows the league fixture based on the weekly match schedule in Table 8. Twelve iterations are shown in Tables 10-21.
Table 6

Distances between stadiums (km)

\begin{tabular}{|c|c|c|c|c|c|c|c|c|}
\hline \multicolumn{7}{|c}{ Teams } \\
\hline & $\mathbf{1}$ & $\mathbf{2}$ & $\mathbf{3}$ & $\mathbf{4}$ & $\mathbf{5}$ & $\mathbf{6}$ & $\mathbf{y}$ & $\mathbf{8}$ \\
\hline $\mathbf{1}$ & 0 & 50 & 60 & 80 & 120 & 182 & 160 & 220 \\
\hline $\mathbf{2}$ & 50 & 0 & 75 & 92 & 90 & 137 & 170 & 196 \\
\hline $\mathbf{3}$ & 60 & 75 & 0 & 100 & 110 & 89 & 150 & 77 \\
\hline $\mathbf{4}$ & 80 & 92 & 100 & 0 & 25 & 94 & 152 & 86 \\
\hline $\mathbf{5}$ & 120 & 90 & 110 & 25 & 0 & 75 & 215 & 69 \\
\hline $\mathbf{6}$ & 182 & 137 & 89 & 94 & 75 & 0 & 50 & 60 \\
\hline $\boldsymbol{7}$ & 160 & 170 & 150 & 152 & 215 & 50 & 0 & 40 \\
\hline $\mathbf{8}$ & 220 & 196 & 77 & 86 & 69 & 60 & 40 & 0 \\
\hline
\end{tabular}


Table 7

League schedule for the first match based on the number of teams

\begin{tabular}{l|l|l|l|l|l|l|l}
\hline \multicolumn{1}{|c}{ 1. Week } \\
\hline 5 & 6 & 8 & 1 & 3 & 4 & 7 & 2 \\
\hline
\end{tabular}

Table 8

Weekly league schedule showing the match of 8 teams for the first match

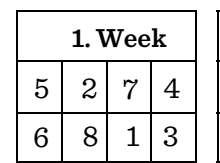

\begin{tabular}{|l|l|l|l|}
\hline \multicolumn{4}{|c|}{ 2. Week } \\
\hline 5 & 6 & 2 & 7 \\
\hline 8 & 1 & 3 & 4 \\
\hline
\end{tabular}

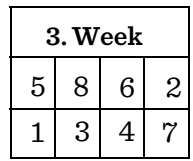

\begin{tabular}{|l|l|l|l|}
\hline \multicolumn{4}{|c|}{ 4. Week } \\
\hline 5 & 1 & 8 & 6 \\
\hline 3 & 4 & 7 & 2 \\
\hline
\end{tabular}

\begin{tabular}{|l|l|l|l|}
\hline \multicolumn{4}{|c|}{ 5. Week } \\
\hline 5 & 3 & 1 & 8 \\
\hline 4 & 7 & 2 & 6 \\
\hline
\end{tabular}

\begin{tabular}{|l|l|l|l|}
\hline \multicolumn{4}{|c|}{ 6. Week } \\
\hline 5 & 4 & 3 & 1 \\
\hline 7 & 2 & 6 & 8 \\
\hline
\end{tabular}

\begin{tabular}{|l|l|l|l|}
\hline \multicolumn{4}{|c|}{ 6. Week } \\
\hline 5 & 7 & 4 & 3 \\
\hline 2 & 6 & 8 & 1 \\
\hline
\end{tabular}

Table 9

League fixture

\begin{tabular}{|c|c|c|c|c|c|c|c|c|c|c|c|c|c|c|c|}
\hline \multirow{2}{*}{\multicolumn{2}{|c|}{ Week }} & \multicolumn{7}{|c|}{ At home } & \multicolumn{7}{|c|}{ At away } \\
\hline & & \multirow{2}{*}{$\begin{array}{l}1 \\
7\end{array}$} & \multirow{2}{*}{$\begin{array}{l}2 \\
6\end{array}$} & \multirow{2}{*}{$\begin{array}{l}3 \\
5\end{array}$} & \multirow{2}{*}{$\begin{array}{l}4 \\
4\end{array}$} & \multirow{2}{*}{$\begin{array}{l}5 \\
2\end{array}$} & \multirow{2}{*}{$\begin{array}{l}6 \\
8\end{array}$} & \multirow{2}{*}{$\begin{array}{l}7 \\
3\end{array}$} & \multirow{2}{*}{\begin{tabular}{l|}
1 \\
7
\end{tabular}} & \multirow{2}{*}{$\begin{array}{l}2 \\
6\end{array}$} & \multirow{2}{*}{$\begin{array}{l}3 \\
5\end{array}$} & \multirow{2}{*}{\begin{tabular}{l|}
4 \\
4
\end{tabular}} & & \multirow{2}{*}{$\begin{array}{l}6 \\
8\end{array}$} & \multirow{2}{*}{$\frac{7}{3}$} \\
\hline \multirow{8}{*}{ 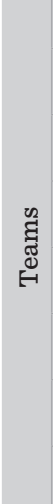 } & 1 & & & & & & & & & & & & & & \\
\hline & 2 & 8 & 3 & 7 & 6 & 1 & 4 & 5 & 8 & 3 & 7 & 6 & 1 & 4 & 5 \\
\hline & 3 & 4 & 2 & 8 & 5 & 7 & 6 & 1 & 4 & 2 & 8 & 5 & 7 & 6 & 1 \\
\hline & 4 & 3 & 7 & 6 & 1 & 5 & 2 & 8 & 3 & 7 & 6 & 1 & 5 & 2 & 8 \\
\hline & 5 & 6 & 8 & 1 & 3 & 4 & 7 & 2 & 6 & 8 & 1 & 3 & 4 & 7 & 2 \\
\hline & 6 & 5 & 1 & 4 & 2 & 8 & 3 & 7 & 5 & 1 & 4 & 2 & 8 & 3 & 7 \\
\hline & 7 & 1 & 4 & 2 & 8 & 3 & 5 & 6 & 1 & 4 & 2 & 8 & 3 & 5 & 6 \\
\hline & 8 & 2 & 5 & 3 & 7 & 6 & 1 & 4 & 2 & 5 & 3 & 7 & 6 & 1 & 4 \\
\hline
\end{tabular}

Movement path for 1 st team: Team 1 will play with team 7 (home), 6 (home), 5 (home), 7 (away), 6 (away), 5 (away), 8 (home), 3 (home), 4 (away), 2 (away), 4 (home), 2 (home), 8 (away), 3 (away) according to the league fixture shown in Table 9.

Looking at the distances between the cities shown in Table 6, it can be found how far the 1st team will move through the league: $d_{1,7}+d_{7,6}+d_{6,5}+d_{5,1}+d_{1,4}+d_{4,2}+d_{2,1}+d_{1,8}+d_{8,3}+d_{3,1}=160+$ $50+75+120+80+92+50+220+77+60=984$.

Similarly, for all other teams, the total mobility during the iteration is shown in Table 10. The league schedule and the total distance the teams have taken based on the first match shown in Table 7 are similarly calculated for the matches shown in Tables 11-21.

Table 10

Total distance the teams took in an iteration according to the first match

\begin{tabular}{|c|c|}
\hline $\begin{array}{l}\text { Total path taken by team } \\
\text { 1: } 984 \\
\text { Total: } 984\end{array}$ & $\begin{array}{l}\text { Total path taken by team } \\
2: 1169 \\
\text { Total: } 2153\end{array}$ \\
\hline $\begin{array}{l}\text { Total path taken by team } \\
3: 1271 \\
\text { Total: } 3424\end{array}$ & $\begin{array}{l}\text { Total path taken by team } \\
4: 993 \\
\text { Total: } 4417\end{array}$ \\
\hline $\begin{array}{l}\text { Total path taken by team } \\
5: 1185 \\
\text { Total: } 5602\end{array}$ & $\begin{array}{l}\text { Total path taken by team } \\
6: 1051 \\
\text { Total: } 6653\end{array}$ \\
\hline $\begin{array}{l}\text { Total path taken by team } \\
\text { r: } 1109 \\
\text { Total: } 7762\end{array}$ & $\begin{array}{l}\text { Total path taken by team } \\
\text { 8: } 1009 \\
\text { Total: } 8771\end{array}$ \\
\hline
\end{tabular}

\section{Table 11}

League schedule for the second match and the total distance the teams took in an iteration

\begin{tabular}{|c|c|c|c|c|c|c|c|}
\hline \multicolumn{8}{|c|}{ 2. Week } \\
\hline 4 & 1 & 7 & 6 & 2 & 3 & 5 & 8 \\
\hline \multicolumn{4}{|c|}{$\begin{array}{l}\text { Total path taken by team } \\
\text { 1: } 1003 \\
\text { Total: } 1003\end{array}$} & \multicolumn{4}{|c|}{$\begin{array}{l}\text { Total path taken by team } \\
2: 938 \\
\text { Total: } 1941\end{array}$} \\
\hline \multicolumn{4}{|c|}{$\begin{array}{l}\text { Total path taken by team } \\
\text { 3: } 895 \\
\text { Total: } 2836\end{array}$} & \multicolumn{4}{|c|}{$\begin{array}{l}\text { Total path taken by team } \\
\text { 4: } 831 \\
\text { Total: } 3667\end{array}$} \\
\hline \multicolumn{4}{|c|}{$\begin{array}{l}\text { Total path taken by team } \\
5: 1010 \\
\text { Total: } 4677\end{array}$} & \multicolumn{4}{|c|}{$\begin{array}{l}\text { Total path taken by team } \\
6: 952 \\
\text { Total: } 5629\end{array}$} \\
\hline \multicolumn{4}{|c|}{$\begin{array}{l}\text { Total path taken by team } \\
7: 1172 \\
\text { Total: } 6801\end{array}$} & \multicolumn{4}{|c|}{$\begin{array}{l}\text { Total path taken by team } \\
8: 1094 \\
\text { Total: } 7895\end{array}$} \\
\hline
\end{tabular}


Table 12

The league schedule for the third match and the total distance the teams took in an iteration

\begin{tabular}{|c|c|c|c|c|c|c|c|}
\hline \multicolumn{8}{|c|}{ 3. Week } \\
\hline 3 & 4 & 5 & 1 & 8 & 6 & 7 & 2 \\
\hline \multicolumn{4}{|c|}{$\begin{array}{l}\text { Total path taken by team } \\
1: 1250 \\
\text { Total: } 1250\end{array}$} & \multicolumn{4}{|c|}{$\begin{array}{l}\text { Total path taken by team } \\
2: 892 \\
\text { Total: } 2142\end{array}$} \\
\hline \multicolumn{4}{|c|}{$\begin{array}{l}\text { Total path taken by team } \\
\text { 3: } 926 \\
\text { Total: } 3068\end{array}$} & \multicolumn{4}{|c|}{$\begin{array}{l}\text { Total path taken by team } \\
\text { 4: } 921 \\
\text { Total: } 3989\end{array}$} \\
\hline \multicolumn{4}{|c|}{$\begin{array}{l}\text { Total path taken by team } \\
\text { 5: } 1080 \\
\text { Total: } 5069\end{array}$} & \multicolumn{4}{|c|}{$\begin{array}{l}\text { Total path taken by team } \\
6: 979 \\
\text { Total: } 6048\end{array}$} \\
\hline \multicolumn{4}{|c|}{$\begin{array}{l}\text { Total path taken by team } \\
\text { r: } 1375 \\
\text { Total: } 7423\end{array}$} & \multicolumn{4}{|c|}{$\begin{array}{l}\text { Total path taken by team } \\
\text { 8: } 1009 \\
\text { Total: } 8432\end{array}$} \\
\hline
\end{tabular}

\section{Table 13}

The league schedule for the fourth match and the total distance the teams took in an iteration

\begin{tabular}{|c|c|c|c|c|c|c|c|}
\hline \multicolumn{8}{|c|}{ 4. Week } \\
\hline 4 & 3 & 6 & 1 & 8 & 7 & 5 & 2 \\
\hline \multicolumn{4}{|c|}{$\begin{array}{l}\text { Total path taken by team } \\
\text { 1: } 1252 \\
\text { Total: } 1252\end{array}$} & \multicolumn{4}{|c|}{$\begin{array}{l}\text { Total path taken by team } \\
2: 955 \\
\text { Total: } 2207\end{array}$} \\
\hline \multicolumn{4}{|c|}{$\begin{array}{l}\text { Total path taken by team } \\
3: 1047 \\
\text { Total: } 3254\end{array}$} & \multicolumn{4}{|c|}{$\begin{array}{l}\text { Total path taken by team } \\
\text { 4: } 936 \\
\text { Total: } 4190\end{array}$} \\
\hline \multicolumn{4}{|c|}{$\begin{array}{l}\text { Total path taken by team } \\
\text { 5: } 979 \\
\text { Total: } 5169\end{array}$} & \multicolumn{4}{|c|}{$\begin{array}{l}\text { Total path taken by team } \\
6: 1041 \\
\text { Total: } 6210\end{array}$} \\
\hline \multicolumn{4}{|c|}{$\begin{array}{l}\text { Total path taken by team } \\
\text { 7: } 1118 \\
\text { Total: } 7328\end{array}$} & \multicolumn{4}{|c|}{$\begin{array}{l}\text { Total path taken by team } \\
\text { 8: } 944 \\
\text { Total: } 8272\end{array}$} \\
\hline
\end{tabular}

The total distance (global minimum) of the teams in the 11 th week was calculated as $7955 \mathrm{~km}$, based on the results obtained in 1 iteration, i.e. 12 weeks, of the algorithm. When the algorithm is run for 100 iterations, the total distance obtained is $7372 \mathrm{~km}$.
Table 14

League schedule for the fifth match and the total distance the teams took in an iteration

\begin{tabular}{|c|c|c|c|c|c|c|c|}
\hline \multicolumn{8}{|c|}{ 5. Week } \\
\hline 5 & 6 & 8 & 1 & 3 & 4 & 7 & 2 \\
\hline \multicolumn{4}{|c|}{$\begin{array}{l}\text { Total path taken by team } \\
\text { 1: } 984 \\
\text { Total: } 984\end{array}$} & \multicolumn{4}{|c|}{$\begin{array}{l}\text { Total path taken by team } \\
2: 1169 \\
\text { Total: } 2153\end{array}$} \\
\hline \multicolumn{4}{|c|}{$\begin{array}{l}\text { Total path taken by team } \\
3: 1271 \\
\text { Total: } 3424\end{array}$} & \multicolumn{4}{|c|}{$\begin{array}{l}\text { Total path taken by team } \\
4: 993 \\
\text { Total: } 4417\end{array}$} \\
\hline \multicolumn{4}{|c|}{$\begin{array}{l}\text { Total path taken by team } \\
5: 1185 \\
\text { Total: } 5602\end{array}$} & \multicolumn{4}{|c|}{$\begin{array}{l}\text { Total path taken by team } \\
6: 1051 \\
\text { Total: } 6653\end{array}$} \\
\hline \multicolumn{4}{|c|}{$\begin{array}{l}\text { Total path taken by team } \\
\text { 7: } 1109 \\
\text { Total: } 7762\end{array}$} & \multicolumn{4}{|c|}{$\begin{array}{l}\text { Total path taken by team } \\
\text { 8: } 1009 \\
\text { Total: } 8771\end{array}$} \\
\hline
\end{tabular}

\section{Table 15}

League schedule for the sixth match and the total distance the teams took in an iteration

\begin{tabular}{|c|c|c|c|c|c|c|c|}
\hline \multicolumn{8}{|c|}{ 6. Week } \\
\hline 4 & 1 & 7 & 5 & 2 & 3 & 6 & 8 \\
\hline \multicolumn{4}{|c|}{$\begin{array}{l}\text { Total path taken by team } \\
\text { 1: } 1064 \\
\text { Total: } 1064\end{array}$} & \multicolumn{4}{|c|}{$\begin{array}{l}\text { Total path taken by team } \\
2: 945 \\
\text { Total: } 2009\end{array}$} \\
\hline \multicolumn{4}{|c|}{$\begin{array}{l}\text { Total path taken by team } \\
\text { 3: } 956 \\
\text { Total: } 2965\end{array}$} & \multicolumn{4}{|c|}{$\begin{array}{l}\text { Total path taken by team } \\
4: 987 \\
\text { Total: } 3952\end{array}$} \\
\hline \multicolumn{4}{|c|}{$\begin{array}{l}\text { Total path taken by team } \\
5: 1093 \\
\text { Total: } 5045\end{array}$} & \multicolumn{4}{|c|}{$\begin{array}{l}\text { Total path taken by team } \\
6: 1035 \\
\text { Total: } 6080\end{array}$} \\
\hline \multicolumn{4}{|c|}{$\begin{array}{l}\text { Total path taken by team } \\
\text { 7: } 1255 \\
\text { Total: } 7335\end{array}$} & \multicolumn{4}{|c|}{$\begin{array}{l}\text { Total path taken by team } \\
\text { 8: } 1079 \\
\text { Total: } 8414\end{array}$} \\
\hline
\end{tabular}

Generally, performances of computational intelligence optimization algorithms in terms of many metrics for a specific complex problem are compared within the same conditions. Due to the stochastic characteristics of the computational intelligence opti- 
Table 16

League schedule for the seventh match and the total distance the teams took in an iteration

\begin{tabular}{|c|c|c|c|c|c|c|c|}
\hline \multicolumn{8}{|c|}{ 7. Week } \\
\hline 3 & 4 & 6 & 1 & 8 & 5 & 7 & 2 \\
\hline \multicolumn{4}{|c|}{$\begin{array}{l}\text { Total path taken by team } \\
\text { 1: } 1194 \\
\text { Total: } 1194\end{array}$} & \multicolumn{4}{|c|}{$\begin{array}{l}\text { Total path taken by team } \\
2: 904 \\
\text { Total: } 2098\end{array}$} \\
\hline \multicolumn{4}{|c|}{$\begin{array}{l}\text { Total path taken by team } \\
3: 1087 \\
\text { Total: } 3185\end{array}$} & \multicolumn{4}{|c|}{$\begin{array}{l}\text { Total path taken by team } \\
\text { 4: } 906 \\
\text { Total: } 4091\end{array}$} \\
\hline \multicolumn{4}{|c|}{$\begin{array}{l}\text { Total path taken by team } \\
\text { 5: } 878 \\
\text { Total: } 4969\end{array}$} & \multicolumn{4}{|c|}{$\begin{array}{l}\text { Total path taken by team } \\
6: 1022 \\
\text { Total: } 5991\end{array}$} \\
\hline \multicolumn{4}{|c|}{$\begin{array}{l}\text { Total path taken by team } \\
\text { r: } 1092 \\
\text { Total: } 7083\end{array}$} & \multicolumn{4}{|c|}{$\begin{array}{l}\text { Total path taken by team } \\
\text { 8: } 1009 \\
\text { Total: } 8092\end{array}$} \\
\hline
\end{tabular}

Table 17

League schedule for the eighth match and the total distance the teams took in an iteration

\begin{tabular}{|c|c|c|c|c|c|c|c|}
\hline \multicolumn{8}{|c|}{ 8. Week } \\
\hline 4 & 3 & 6 & 1 & 8 & 7 & 5 & 2 \\
\hline \multicolumn{4}{|c|}{$\begin{array}{l}\text { Total path taken by team } \\
\text { 1: } 1252 \\
\text { Total: } 1252\end{array}$} & \multicolumn{4}{|c|}{$\begin{array}{l}\text { Total path taken by team } \\
\text { 2: } 955 \\
\text { Total: } 2207\end{array}$} \\
\hline \multicolumn{4}{|c|}{$\begin{array}{l}\text { Total path taken by team } \\
3: 1047 \\
\text { Total: } 3254\end{array}$} & \multicolumn{4}{|c|}{$\begin{array}{l}\text { Total path taken by team } \\
\text { 4: } 936 \\
\text { Total: } 4190\end{array}$} \\
\hline \multicolumn{4}{|c|}{$\begin{array}{l}\text { Total path taken by team } \\
\text { 5: } 979 \\
\text { Total: } 5169\end{array}$} & \multicolumn{4}{|c|}{$\begin{array}{l}\text { Total path taken by team } \\
6: 1041 \\
\text { Total: } 6210\end{array}$} \\
\hline \multicolumn{4}{|c|}{$\begin{array}{l}\text { Total path taken by team } \\
\text { 7: } 1118 \\
\text { Total: } 7328\end{array}$} & \multicolumn{4}{|c|}{$\begin{array}{l}\text { Total path taken by team } \\
\text { 8: } 944 \\
\text { Total: } 8272\end{array}$} \\
\hline
\end{tabular}

mization algorithms, the performance of the algorithm can be understood by interpreting the results after at least 30 runs. In this study, League Championship Algorithm (LCA) has been selected for performance comparisons. OIO and LCA were run 30 times for both 1 (iteration, season) and 100 (iterations, seasons). For statistical analysis, t-test method has been performed.

\section{Table 18}

League schedule for the ninth match and the total distance the teams took in an iteration

\begin{tabular}{|c|c|c|c|c|c|c|c|}
\hline \multicolumn{8}{|c|}{ 9. Week } \\
\hline 4 & 6 & 8 & 1 & 3 & 5 & 7 & 2 \\
\hline \multicolumn{4}{|c|}{$\begin{array}{l}\text { Total path taken by team } \\
\text { 1: } 1001 \\
\text { Total: } 1001\end{array}$} & \multicolumn{4}{|c|}{$\begin{array}{l}\text { Total path taken by team } \\
2: 1169 \\
\text { Total: } 2170\end{array}$} \\
\hline \multicolumn{4}{|c|}{$\begin{array}{l}\text { Total path taken by team } \\
\text { 3: } 1206 \\
\text { Total: } 3376\end{array}$} & \multicolumn{4}{|c|}{$\begin{array}{l}\text { Total path taken by team } \\
4: 1103 \\
\text { Total: } 4479\end{array}$} \\
\hline \multicolumn{4}{|c|}{$\begin{array}{l}\text { Total path taken by team } \\
\text { 5: } 965 \\
\text { Total: } 5444\end{array}$} & \multicolumn{4}{|c|}{$\begin{array}{l}\text { Total path taken by team } \\
6: 1051 \\
\text { Total: } 6495\end{array}$} \\
\hline \multicolumn{4}{|c|}{$\begin{array}{l}\text { Total path taken by team } \\
\text { 7: } 1103 \\
\text { Total: } 7598\end{array}$} & \multicolumn{4}{|c|}{$\begin{array}{l}\text { Total path taken by team } \\
8: 1024 \\
\text { Total: } 8622\end{array}$} \\
\hline
\end{tabular}

Table 19

The league schedule for the tenth match and the total distance the teams took in an iteration

\begin{tabular}{|c|c|c|c|c|c|c|c|}
\hline \multicolumn{8}{|c|}{ 10. Week } \\
\hline 5 & 1 & 4 & 7 & 2 & 3 & 6 & 8 \\
\hline \multicolumn{4}{|c|}{$\begin{array}{l}\text { Total path taken by team } \\
\text { 1: } 1300 \\
\text { Total: } 1300\end{array}$} & \multicolumn{4}{|c|}{$\begin{array}{l}\text { Total path taken by team } \\
2: 1012 \\
\text { Total: } 2312\end{array}$} \\
\hline \multicolumn{4}{|c|}{$\begin{array}{l}\text { Total path taken by team } \\
3: 1192 \\
\text { Total: } 3504\end{array}$} & \multicolumn{4}{|c|}{$\begin{array}{l}\text { Total path taken by team } \\
\text { 4: } 1095 \\
\text { Total: } 4599\end{array}$} \\
\hline \multicolumn{4}{|c|}{$\begin{array}{l}\text { Total path taken by team } \\
5: 1046 \\
\text { Total: } 5645\end{array}$} & \multicolumn{4}{|c|}{$\begin{array}{l}\text { Total path taken by team } \\
6: 1037 \\
\text { Total: } 6682\end{array}$} \\
\hline \multicolumn{4}{|c|}{$\begin{array}{l}\text { Total path taken by team } \\
\text { 7: } 1248 \\
\text { Total: } 7930\end{array}$} & \multicolumn{4}{|c|}{$\begin{array}{l}\text { Total path taken by team } \\
8: 1051 \\
\text { Total: } 8981\end{array}$} \\
\hline
\end{tabular}

In order to compare the performance of the OIO algorithm with the LCA, the same iteration parameters have been used. LightPoint value is selected as 12 in OIO algorithm. In LCA, the number of teams (Team) is 4. LightPoint is set to this value because there will be a total of 12 matches during the season, as it is 4 teams in the league and 3 weeks a season. $N$ value 
Table 20

The league schedule for the eleventh match and the total distance the teams took in an iteration

\begin{tabular}{|c|c|c|c|c|c|c|c|}
\hline \multicolumn{8}{|c|}{ 11. Week } \\
\hline 3 & 6 & 5 & 1 & 8 & 4 & 7 & 2 \\
\hline \multicolumn{4}{|c|}{$\begin{array}{l}\text { Total path taken by team } \\
\text { 1: } 990 \\
\text { Total: } 990\end{array}$} & \multicolumn{4}{|c|}{$\begin{array}{l}\text { Total path taken by team } \\
2: 1005 \\
\text { Total: } 1995\end{array}$} \\
\hline \multicolumn{4}{|c|}{$\begin{array}{l}\text { Total path taken by team } \\
3: 1002 \\
\text { Total: } 2997\end{array}$} & \multicolumn{4}{|c|}{$\begin{array}{l}\text { Total path taken by team } \\
4: 717 \\
\text { Total: } 3714\end{array}$} \\
\hline \multicolumn{4}{|c|}{$\begin{array}{l}\text { Total path taken by team } \\
\text { 5: } 876 \\
\text { Total: } 4590\end{array}$} & \multicolumn{4}{|c|}{$\begin{array}{l}\text { Total path taken by team } \\
6: \text { r75 } \\
\text { Total: } 5365\end{array}$} \\
\hline \multicolumn{4}{|c|}{$\begin{array}{l}\text { Total path taken by team } \\
\text { 7: } 1115 \\
\text { Total: } 6480\end{array}$} & \multicolumn{4}{|c|}{$\begin{array}{l}\text { Total path taken by team } \\
\text { 8: } 1066 \\
\text { Total: } 7546\end{array}$} \\
\hline
\end{tabular}

\section{Table 21}

The league schedule for the twelfth match and the total distance the teams took in an iteration

\begin{tabular}{|c|c|c|c|c|c|c|c|}
\hline \multicolumn{8}{|c|}{ 12. Week } \\
\hline 4 & 3 & 5 & 1 & 8 & 7 & 6 & 2 \\
\hline \multicolumn{4}{|c|}{$\begin{array}{l}\text { Total path taken by team } \\
\text { 1: } 1240 \\
\text { Total: } 1240\end{array}$} & \multicolumn{4}{|c|}{$\begin{array}{l}\text { Total path taken by team } \\
2: 955 \\
\text { Total: } 2195\end{array}$} \\
\hline \multicolumn{4}{|c|}{$\begin{array}{l}\text { Total path taken by team } \\
\text { 3: } 991 \\
\text { Total: } 3186\end{array}$} & \multicolumn{4}{|c|}{$\begin{array}{l}\text { Total path taken by team } \\
4: 1011 \\
\text { Total: } 4197\end{array}$} \\
\hline \multicolumn{4}{|c|}{$\begin{array}{l}\text { Total path taken by team } \\
\text { 5: } 1106 \\
\text { Total: } 5303\end{array}$} & \multicolumn{4}{|c|}{$\begin{array}{l}\text { Total path taken by team } \\
6: 1136 \\
\text { Total: } 6439\end{array}$} \\
\hline \multicolumn{4}{|c|}{$\begin{array}{l}\text { Total path taken by team } \\
\text { r: } 1206 \\
\text { Total: } 7645\end{array}$} & \multicolumn{4}{|c|}{$\begin{array}{l}\text { Total path taken by team } \\
\text { 8: } 966 \\
\text { Total: } 8611\end{array}$} \\
\hline
\end{tabular}

refers to the problem dimension and $N$ was selected as 8 in both algorithms. In contrast to the number of seasons in LCA, the maximum iteration value in OIO algorithm is 100. LCA and OIO for 1 season or iteration and 100 seasons or iterations used in the total distance optimization in the TTP have been run and the performances of both optimization algorithms on this problem have been measured. The total minimum distance obtained is shown in Table 22.
Table 22

Comparison of OIO and LCA $(\mathrm{km})$

\begin{tabular}{|c|c|c|c|c|}
\hline $\begin{array}{l}\text { Number } \\
\text { of Run }\end{array}$ & $\begin{array}{c}\text { OIO (1 } \\
\text { iteration) }\end{array}$ & $\begin{array}{r}\text { LCA (1 } \\
\text { season) }\end{array}$ & $\begin{array}{c}\text { OIO (100 } \\
\text { iterations) }\end{array}$ & $\begin{array}{c}\text { LCA (100 } \\
\text { seasons) }\end{array}$ \\
\hline 1 & 7955 & 8417 & 7372 & 7362 \\
\hline 2 & 7897 & 8074 & 7409 & 7625 \\
\hline 3 & 7886 & 8393 & 7415 & 7546 \\
\hline 4 & 8024 & 8115 & 7480 & 7511 \\
\hline 5 & 8288 & 8123 & 7406 & 7362 \\
\hline 6 & 7682 & 8038 & 7429 & 7569 \\
\hline 7 & 7597 & 8078 & 7394 & 7415 \\
\hline 8 & r7y04 & 8062 & 7459 & 7519 \\
\hline 9 & 7730 & 7902 & 7362 & 7405 \\
\hline 10 & 8169 & 7744 & 7385 & 7530 \\
\hline 11 & 7985 & 7575 & 7516 & 7495 \\
\hline 12 & 8042 & 8024 & 7478 & 7453 \\
\hline 13 & 7716 & raryry & 7505 & 7362 \\
\hline 14 & 7937 & 7980 & 7338 & 7512 \\
\hline 15 & 7966 & 8496 & 7295 & 7511 \\
\hline 16 & 7581 & 8237 & 7449 & 7400 \\
\hline 17 & 8040 & 8274 & 7530 & 7563 \\
\hline 18 & 7858 & 8130 & 7496 & 7554 \\
\hline 19 & 8177 & 8649 & 7394 & 7575 \\
\hline 20 & 7973 & 8310 & 7540 & 7600 \\
\hline 21 & 7849 & 7845 & 7453 & 7347 \\
\hline 22 & 7516 & 7861 & 7386 & 7295 \\
\hline 23 & 7850 & r7793 & 7400 & 7340 \\
\hline 24 & 7933 & 7945 & 7340 & 7338 \\
\hline 25 & 7878 & 8019 & 7482 & 7347 \\
\hline 26 & 7507 & 7809 & 7358 & 7470 \\
\hline 27 & 7842 & 7876 & 7491 & 7539 \\
\hline 28 & 8036 & 8152 & 7360 & 7372 \\
\hline 29 & r7794 & 8373 & 7603 & 7629 \\
\hline 30 & 7899 & 7693 & 7347 & 7519 \\
\hline
\end{tabular}


The t-test results obtained by running LCA and OIO algorithms for 1 season or iteration are shown in Table 23, and the t-test results obtained by running 100 seasons or iterations are shown in Table 24.

\section{Table 23}

t-test results obtained by 1 season-iteration operation of LCA and OIO algorithm

\begin{tabular}{l|l|l}
\hline & \multicolumn{1}{|c|}{ LCA } & \multicolumn{1}{c}{ OIO } \\
\hline Mean & 8058.8 & 7877.033333 \\
\hline Variance & 65023.06207 & 36074.65402 \\
\hline Observations & 30 & 30 \\
\hline Hypothesized Mean & 0 & \\
\hline$t$ Stat & 3.59930922 & \\
\hline$P(T<=t)$ one-tail & 0.000586497 & \\
\hline$t$ Critical one-tail & 1.699127027 & \\
\hline$P(T<=t)$ two-tail & 0.001172994 & \\
\hline$t$ Critical two-tail & 2.045229642 & \\
\hline
\end{tabular}

Table 24

t-test results obtained by 100 season-iteration operations of LCA and OIO algorithm

\begin{tabular}{l|l|l}
\hline & \multicolumn{1}{|c|}{ LCA } & \multicolumn{1}{c}{ OIO } \\
\hline Mean & 7482.233333 & 7429.066667 \\
\hline Variance & 16078.25402 & 5199.512644 \\
\hline Observations & 30 & 30 \\
\hline Hypothesized Mean & 0 & \\
\hline$t$ Stat & 2.170686074 & \\
\hline$P(T<=t)$ one-tail & 0.019141499 & \\
\hline$t$ Critical one-tail & 1.699127027 & \\
\hline$P(T<=t)$ two-tail & 0.038282999 & \\
\hline$t$ Critical two-tail & 2.045229642 & \\
\hline
\end{tabular}

In the t-test;

$H_{0}$ : It is argued that there is no difference between the means.

$H_{a}$ : It is argued that there is a meaningful difference between the means.
$P$ : Probability value

Observations: Number of experiments

$t$ Stat: $t$ statistic value

Pearson Correlation: The correlation coefficient between LCA and OIO samples

$t$ Critical one-tail: Single-sided $t$ critical value

$t$ Critical two-tail: Double-sided $t$ critical value

alfa: Significant level

In the t-test, there are two hypotheses, $H_{0}$ and $H_{a}$. When the $P$ value is less than 0.05 , the $H_{0}$ hypothesis is rejected and $H_{a}$ is accepted. When the $P$ value is greater than or equal to 0.05 , the $H_{0}$ hypothesis is accepted and $H_{a}$ is rejected. $H_{0}$ hypothesis will be "The convergence value of OIO to global minimum is not lower than the convergence value of LCA to global minimum, there is no difference between the mean values of the obtained minimum values". $H_{a}$ hypothesis will be "The convergence value of OIO to the global minimum is lower than the convergence value of LCA to global minimum, meaning there is a significant difference between the means".

According to the $P$ values shown in Table 27 , it is seen that single-ended 0.0005 and double-ended 0.001, both values being less than 0.05 . The $H_{0}$ hypothesis is rejected and $H_{a}$ is accepted. OIO algorithm has shown better results than LCA for 1 season-iteration. According to t-test results, OIO's success has been found to be statistically better than LCA in 30 experiments. According to the $P$ values shown in Table 28, it is seen that single-ended 0.01 and double-ended 0.03, both values being less than 0.05. The $H_{0}$ hypothesis is rejected and $H_{a}$ is accepted. OIO algorithm has shown better results than LCA for 100 season-iteration. According to t-test results, OIO's success has been found to be statistically better than LCA in 30 experiments.

Another experiment has been performed within real dataset NL8 obtained from [30] as shown in Table 25. The same parameters have been selected as used in synthetic dataset. Two algorithms have been executed 30 times. The obtained distances are listed in Table 26. OIO seems to perform better than LCA, however, the differences between mean values are not statistically important as evidenced by the t-test results shown in Table 27. 


\section{Table 25}

Distances between stadiums $(\mathrm{km})$

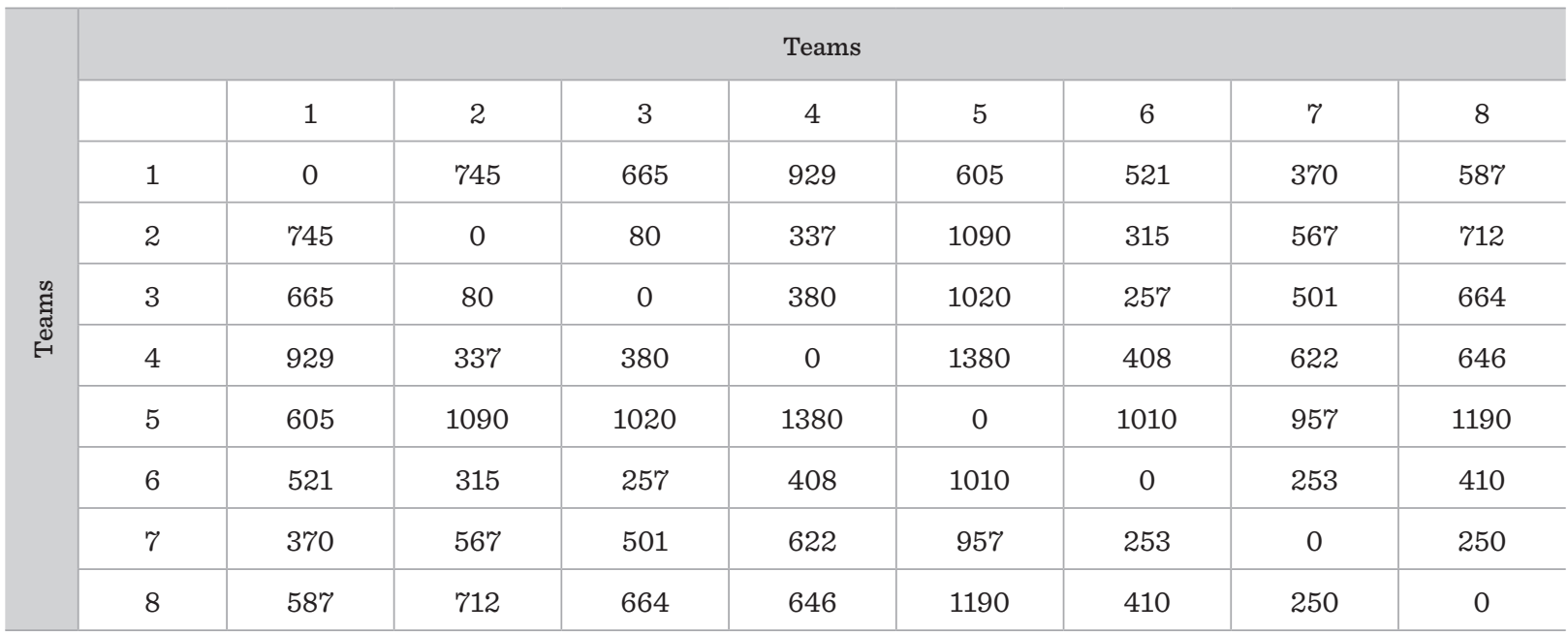

Table 26

Comparison of LCA and OIO algorithms within NL8 dataset

\begin{tabular}{|c|c|c|c|c|c|}
\hline $\begin{array}{l}\text { Number of } \\
\text { Run }\end{array}$ & OIO (100 iterations) & LCA (100 seasons) & Number of Run & OIO (100 iterations) & LCA (100 seasons) \\
\hline 1 & 45242 & 45357 & 16 & 45815 & 45460 \\
\hline 2 & 45752 & 45242 & 17 & 45376 & 46452 \\
\hline 3 & 45452 & 45242 & 18 & 45374 & 45242 \\
\hline 4 & 45438 & 45399 & 19 & 45438 & 45564 \\
\hline 5 & 45433 & 45815 & 20 & 45706 & 45452 \\
\hline 6 & 45821 & 45242 & 21 & 45492 & 46009 \\
\hline 7 & 45460 & 46002 & 22 & 45433 & 45242 \\
\hline 8 & 45357 & 45677 & 23 & 45242 & 45857 \\
\hline 9 & 45438 & 45357 & 24 & 45242 & 46002 \\
\hline 10 & 45357 & 45752 & 25 & 45242 & 45522 \\
\hline 11 & 45997 & 45633 & 26 & 45357 & 46673 \\
\hline 12 & 45242 & 45564 & 27 & 45564 & 45564 \\
\hline 13 & 45581 & 46275 & 28 & 45438 & 45433 \\
\hline 14 & 45941 & 46002 & 29 & 45564 & 45242 \\
\hline 15 & 45857 & 45492 & 30 & 45581 & 45374 \\
\hline & & & Mean & 45507.73 & 45637.97 \\
\hline
\end{tabular}


Table 27

t-test results of LCA and OIO within real NL8 dataset

\begin{tabular}{l|l|l}
\hline & \multicolumn{1}{|c|}{ LCA } & \multicolumn{1}{c}{ OIO } \\
\hline Mean & 45507.73333 & 45637.96667 \\
\hline Variance & 46565.71954 & 143230.723 \\
\hline Observations & 30 & 30 \\
\hline Hypothesized Mean & 0 & \\
\hline$t$ Stat & -1.530079783 & \\
\hline$P(T<=t)$ one-tail & 0.068416633 & \\
\hline$t$ Critical one-tail & 1.699127027 & \\
\hline$P(T<=t)$ two-tail & 0.136833266 & \\
\hline$t$ Critical two-tail & 2.045229642 &
\end{tabular}

\section{Conclusions}

Problems encountered in sports sciences such as traveling tournament problem, referee appointment problem, tournament planning, qualification and elimination problems, minimization of moving problems are difficult to be efficiently solved. Novel and computationally efficient methods should be searched for these search and optimization problems. OIO is one of the most recent physics-based algorithm that can be effectively used to solve such problems.

In this study, LCA and OIO were used for the first time to solve the Traveling Tournament Problem for

\section{References}

1. Akyol, S., Alatas, B. Automatic Mining of Accurate and Comprehensible Numerical Classification Rules with Cat Swarm Optimization Algorithm. Journal of the Faculty of Engineering and Architecture of Gazi University, 2016, 31(4), 839-857. https://doi.org/10.17341/ gazimmfd.278440

2. Akyol, S., Alatas, B. Güncel Sürü Zekası Optimizasyon Algoritmaları. Nevsehir Journal of Science and Technology, 2012, 1(1) 36-50.

3. Akyol, S., Alatas, B. Plant Intelligence Based Metaheuristic Optimization Algorithms. Artificial Intelligence Review, 2017, 47(4), 417-462. https://doi. org/10.1007/s10462-016-9486-6

4. Alatas, B. ACROA: Artificial Chemical Reaction Optimization Algorithm for Global Optimization. Expert which the total movement of the teams of the games has been aimed to be minimized considering the constraints. The results obtained from OIO are compared with the results obtained from LCA which is one of the most recent artificial intelligence based optimization algorithms.

In the formed artificial league, the total movement of all the teams obtained from OIO in the 1st season was $8417 \mathrm{~km}$. When the algorithm's season number is set to 100 , the total mobility has decreased to $7362 \mathrm{~km}$. Similarly, the total movement of all the teams obtained from LCA in the 1st iteration was $7955 \mathrm{~km}$. When the algorithm's iteration number is set to 100 , the total mobility has decreased to $7372 \mathrm{~km}$. These two new algorithms have been also used for a real dataset and OIO seems to perform better than LCA. Although OIO is very new, the obtained results are promising and OIO seems to be an alternative method for the complex search and optimization problems for which mathematical model cannot be created or takes too long for computing even if it is created. Distributed and parallel versions of OIO and LCA with optimized parameters can be proposed for many different complex problems.

\section{Acknowledgments}

We would like to present our thanks to anonymous reviewers and the esteemed editors for their helpful suggestions.

Systems with Applications, 2011, 38(10), 13170-13180. https://doi.org/10.1016/j.eswa.2011.04.126

5. Altay E. V., Alatas, B., Bird Swarm Algorithms with Chaotic Mapping. Artificial Intelligence Review, 2019. https://doi.org/10.1007/s10462-019-09704-9

6. Anagnostopoulos, A., Michel, L., Hentenryck, P., Vergados, Y. A Simulated Annealing Approach to the Travelling Tournament Problem. Journal of Scheduling, 2006, 9(2), 177-193. https://doi.org/10.1007/s10951006- $7187-8$

7. Benoist, T., Laburthe, F., Rottembourg B. Lagrange Relaxation and Constraint Programming Collaborative Schemes for Travelling Tournament Problems. CP-AIOR'2001,Wye College (Imperial College), Ashford, Kent $\mathrm{UK}, 2001$. 
8. Borji, A., Hamidi, M. A New Approach to Global Optimization Motivated by Parliamentary Political Competitions. International Journal of Innovative Computing. Information and Control, 2009, 5(6), 643-1653.

9. Can, U., Alatas, B. Physics Based Metaheuristic Algorithms for Global Optimization. American Journal of Information Science and Computer Engineering, 2015, 1(3), 94-106.

10. Cardemil, A. Optimizacion de Fixtures Deportivos: Estado del Arte y Un Algoritmo Tabu Search Para el Travelling Tournament Problem. Master thesis, Departamento de Computaci Ón Facultad de Ciencias Exactas y Naturales Universidad de Buenos Aires, 2002.

11. Chen, P., Kendall, G., Berghe, G. V. An Ant Based Hyper-Heuristic for the Travelling Tournament Troblem. Proceedings of IEEE Symposium of Computational Intelligence in Scheduling, 2007, 19-26. https://doi. org/10.1109/SCIS.2007.367665

12. Choubey, N. S. A Novel Encoding Scheme for Traveling Tournament Problem using Genetic Algorithm. IJCA Special Issue on Evolutionary Computation for Optimization Techniques, 2010, 79-82. https://doi. org/10.5120/1536-139

13. Crauwels, H., Oudheusden, D. V. Ant Colony Optimization and Local Improvement. The Third Workshop on Real-Life Applications of Metaheuristics, Antwerp, Belgium, 2003.

14. De Castro, L. N., Von Zuben, F. J. Learning and Optimization Using the Clonal Selection Principle. IEEE Transactions on Evolutionary Computation, 2002, 6(3), 239-251. https://doi.org/10.1109/TEVC.2002.1011539

15. Dorigo, M., Maniezzo, V., Colorni, A. The Ant System: An Autocatalytic Optimizing Process. Technical Report No. 91- 016, Dipartimento di Elettronica, Politecnico di Milano, 1991, Italy.

16. Easton, K., Nemhauser, G. L., Trick, M. A. Solving The Travelling Tournament Problem: A Combined Integer Programming and Constraint Programming Approach. 4th International Conference on the Practice and Theory of Automated Timetabling. Gent, Belgium, 2002, 319-330.

17. Easton, K., Nemhauser, G. L., Trick, M. A. The Travelling Tournament Problem: Description and Benchmarks. Principles and Practice of Constraint Programming. Springer, LNCS 2239, 2001, 580-585. https://doi. org/10.1007/3-540-45578-7_43

18. Gaspero, L. D., Schaerf, A. A Composite-Neighborhood Tabu Search Approach to The Travelling Tournament Problem. Journal of Heuristics, 2007, 13(2), 189-20\%. https://doi.org/10.1007/s10732-006-9007-x
19. Geem, Z. W., Kim, J. H., Loganathan, G. V. A New Heuristic Optimization Algorithm: Harmony Search. Simulation. 2001, 76, 60-68. https://doi. org/10.117r7/003754970107600201

20. Gupta, D., Goel, L., Chopra, A. Enhanced Heuristic Approach for Travelling Tournament Problem Based on Extended Species Abundance Models of Biogeography. International Conference on Advances in Computing, Communications and Informatics, 2014, 1118-1124. https://doi.org/10.1109/ICACCI.2014.6968336

21. Holland, J. H. Adaption in Natural and Artificial Systems. University of Michigan Pres., 1975. Ann Arbor, MI.

22. Javidy, B., Hatamlou, A., Mirjalili, S. Ions Motion Algorithm for Solving Optimization Problems. Applied Soft Computing, 2015, 32, 72-79. https://doi.org/10.1016/j. asoc.2015.03.035

23. Kashan, A. H. A New Metaheuristic for Optimization: Optics Inspired Optimization (OIO). Computers \& Operations Research, 2015, 55, 99-125. https://doi. org/10.1016/j.cor.2014.10.011

24. Kashan, A. H. An Effective Algorithm for Constrained Optimization based on Optics Inspired Optimization (OIO). Computer-Aided Design, 2015, 63, 52-71. https:// doi.org/10.1016/j.cad.2014.12.007

25. Kashan, A. H. League Championship Algorithm (LCA): An Algorithm for Global Optimization inspired by Sport Championships. Applied Soft Computing, 2014, 16, 171200. https://doi.org/10.1016/j.asoc.2013.12.005

26. Kennedy, J., Eberhart, R. C. Particle Swarm Optimization. IEEE International Conference on Neural Networks, Piscataway, NJ, 1995, 1942-1948.

27. Kim, B. M. Iterated Local Search for the Traveling Tournament Problem. Master Thesis, 2012, Austria.

28. Kiziloluk, S., Alatas, B. Current Social-Based Heuristic Optimization Algorithms. Cumhuriyet University Journal of Economics and Administrative Sciences, 2012, 13(2), 39-56.

29. Lalwani, P., Banka, H., Kumar, C. CRWO: Clustering and Routing in Wireless Sensor Networks using Optics Inspired Optimization. Peer-to-Peer Networking and Applications, 2017, 10(3), 453-471. https://doi. org/10.1007/s12083-016-0531-7

30. Langford, Challenging Travelling Tournament Instances. http://mat.gsia.cmu.edu/TOURN/, Accessed on February 01, 2018.

31. Lim, A., Rodrigues, B., Zhang, X. A Simulated Annealing and Hill-Climbing Algorithm for the Traveling Tournament Problem. European Journal of Opera- 
tional Research, 2006, 174(3), 1459-1478. https://doi. org/10.1016/j.ejor.2005.02.065

32. Meng, X., Liu, Y., Gao, X., Zhang, H. A New Bio-Inspired Algorithm: Chicken Swarm Optimization. International Conference in Swarm Intelligence, Springer International Publishing, 2014, 86-95. https://doi. org/10.1007/978-3-319-11857-4_10

33. Mora-Gutiérrez, R. A., Ramírez-Rodríguez, J., RincónGarcía, E. A. An Optimization Algorithm inspired by Musical Composition. Artificial Intelligence Review, 2014, 41(3), 301-315. https://doi.org/10.1007/s10462-011-9309-8

34. Nemhauser, G. L., Trick, M. A. Scheduling a Major College Basketball Conference. Operations Research, 1998, 46(1), 1-8. https://doi.org/10.1287/opre.46.1.1

35. Ozbay, F. A., Alatas, B. Review of Computational Intelligence Method Inspired from Behavior of Water. Afyon Kocatepe University Journal of Science and Engineering, 2016, 16, 137-147.

36. Ozbay, F. A., Alatas, B. Review of Social-Based Artificial Intelligence Optimization Algorithms for Social Network Analysis. International Journal of Pure and Applied Sciences, 2015, 1, 33-52.

37. Pérez-Cáceres, L., Riff, M. C. Solving Scheduling Tournament Problems Using a New Version of CLONALG. Connection Science, 2015, 27(1), 5-21. https://doi.org/1 $0.1080 / 09540091.2014 .944099$

38. Ramezani, F., Lotfi, S. Social-Based Algorithm (SBA). Applied Soft Computing, 2013, 13(5), 2837-2856. https://doi.org/10.1016/j.asoc.2012.05.018

39. Rao, R. V. Savsani, V. J., Vakharia, D. P. Teaching-Learning-Based Optimization: An Optimization Method for Continuous Non-Linear Large Scale Problems. Information Sciences, 2012, 183(1), 1-15. https://doi. org/10.1016/j.ins.2011.08.006
40. Russell, R. A., Leung J. M. Devising a Cost Effective Schedule for a Baseball League. Operations Research, 1994, 42(4), 614-625. https://doi.org/10.1287/ opre.42.4.614

41. Ryckbosch, F., Berghe, G. V., Kendall, G. A Heuristic Approach for the Travelling Tournament Problem Using Optimal Travelling Salesman Tours. Proceedings of the rth International Conference on the Practice and Theory of Automated Timetabling, 2008.

42. Salem, S. A. BOA: A Novel Optimization Algorithm. IEEE International Conference on Engineering and Technology, 2012, 1-5. https://doi.org/10.1109/ ICEngTechnol.2012.6396156

43. Shen, H., Zhang, H. Greedy Big Steps As a Meta-Heuristic for Combinatorial Search. The University of Iowa AR Reading Group, Spring 2004 Readings.

44. Tamgave, P., Jain, S., Waghmode, G., Udagire, S., Umale, J. Optimization of Travelling Tournament Problem using Nature Based Algorithms. International Journal of Innovative Research in Science, Engineering and Technology, 2014, 3(2), 9395-9402.

45. Tanyildizi, E., Demir, G. Golden Sine Algorithm: A Novel Math-Inspired Algorithm. Advances in Electrical and Computer Engineering, 2017, 17(2), 71-78. https://doi. org/10.4316/AECE.2017.02010

46. Tayarani-N, M. H., Akbarzadeh-T, M. R. Magnetic Optimization Algorithms a New Synthesis. IEEE Congress on Evolutionary Computation, 2008, 2659-2664. https://doi.org/10.1109/CEC.2008.4631155

47. Xing, B., Gao, W. J. Central Force Optimization Algorithm. Innovative Computational Intelligence: A Rough Guide to 134 Clever Algorithms. Springer International Publishing, 2014, 333-337. https://doi.org/10.1007/9783-319-03404-1_19 